\title{
Investigating Determinants of Knowledge about HIV Prevention among Young in Ethiopia
}

\author{
Dereje Bekele Dessie ${ }^{1, *}$ \\ ${ }^{1}$ Department of Statistics, College of Natural and Computational Science, Madda Walabu University, PO Box 247, \\ Bale-Robe, Ethiopia \\ *Correspondence: Department of Statistics, College of Natural and Computational Science, Madda Walabu \\ University, PO Box 247. Bale-Robe, Ethiopia. E-mail: dereje1999@gmail.com
}

Received: January 10, 2020 Accepted: January 19, 2020 Online Published: January 22, 2020

doi:10.5430/wjss.v7n1p46 URL: https://doi.org/10.5430/wjss.v7n1p46

\begin{abstract}
Knowledge about HIV prevention means knowing that consistent use of condoms during sexual intercourse, having one uninfected faithful partner can reduce chance of getting HIV, knowing that a healthy-looking person can have HIV, rejecting the two most common local misconceptions (HIV can be transmitted by mosquito bites and a person can become infected by sharing food with a person who has HIV). The study objective was to assess and identify determinants of comprehensive knowledge about HIV prevention among young in Ethiopia. The data used for analysis was 2016 EDHS. The dependent variable was comprehensive knowledge about HIV prevention and Descriptive statistics and Binary logistic regression used to identify determinants of comprehensive knowledge about HIV prevention among young. The study conducted on 10,520 young, of which $41.9 \%$ were male and $58.1 \%$ female. The significant determinants of comprehensive knowledge about HIV prevention among young were age, residence, education, occupation, marital status, wealth index, sex, region and media exposure. In conclusion, Young with low income, single, male without formal education were less likely to have comprehensive knowledge while the knowledge status is different from region to region. Education for low income, single and male on HIV prevention must be expanded to improve knowledge of the disease in Ethiopia.
\end{abstract}

Keywords: 15-24 years young, comprehensive knowledge, prevention, HIV, determinants, logistic regression

\section{Introduction}

Knowledge about human immunodeficiency (HIV) prevention means knowing that consistent use of condoms during sexual intercourse and having just one uninfected faithful partner can reduce the chance of getting HIV, knowing that a healthy-looking person can have HIV, and rejecting the two most common local misconceptions about transmission or prevention of HIV (that HIV can be transmitted by mosquito bites and that a person can become infected by sharing food with a person who has HIV) (Bradley, S. et al., 2012).

Worldwide $50 \%$ of all HIV positive people are women. In Africa, HIV positive women constitute about $60 \%$ of all HIV positive people (UNAIDS, 2008). Gender inequities in society are recognized as playing a key role in driving the HIV epidemic, particularly in respect to women.

Globally, the status of the HIV pandemic is relatively bleak, with a continuous rise in the population of people living with HIV. According to the Joint United Nations Program on HIV/AIDS (UNAIDS) and World Health Organization (UNAIDS \& WHO, 2009). Approximately 33.4 million people worldwide are living with HIV, of which 31.3 million are adults, 15.7 million are women and 2.1 million are children under the age of 15 years.

The major health problems of the country remain largely preventable communicable diseases and nutritional disorders. Moreover, $6 \%$ of all maternal deaths were attributable to complications from abortion. Shortage of skilled midwives, weak referral system at health centre levels, lack of inadequate availability of equipment and under financing of the service were identified as major supply side constraints that hindered progress while cultural norms and societal emotional support bestowed to mothers, distance to functioning health centers and financial barrier were found to be the major causes (FDRE MoH, 2010). 
The growing effectiveness of Ethiopia's HIV response has resulted in a dramatic decline in HIV incidence (CDC Ethiopia Fact sheet, 2013). Ethiopian 2010 millennium development goal report revealed that In terms of progress towards the universal targets set in the 'Millennium AIDS campaign,' data from UNAIDS shows that Antiretroviral therapy (ART) care and support for people living with the virus, counseling and testing programs to support orphans and vulnerable children are on track, while coverage of mother-to child prevention services is lagging behind.

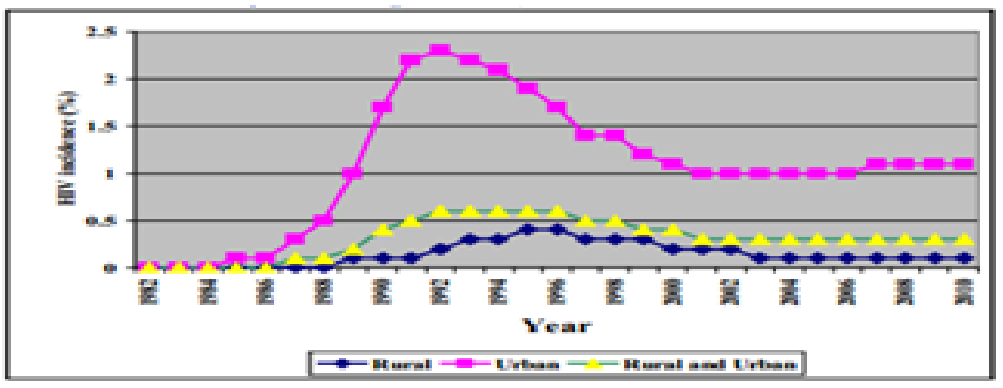

Source: $6^{\text {th }}$ Annual Report on AIDS in Ethiopia-MoH/HAPCO

Figure 1. Estimated and Projected HIV Incidence by Year, Rural, Urban and National (Population Aged 15-49)

In Ethiopia, $24 \%$ of young women and 39\% of young men 15-24 have knowledge about HIV prevention. Among both sexes, urban youth are more likely than rural youth to have knowledge about HIV prevention. The percentage of youth with knowledge about HIV prevention is lower among those ages 15-17 than among older youth, especially for men. Ever married young women are much less likely than other women (19\%) to have this knowledge, a pattern not observed for men. Urban youth, those living in Addis Ababa, youth with more than a secondary education, and youth from the wealthiest households are more likely than other subgroups to have knowledge about HIV prevention. Increasing general knowledge about prevention of HIV from mother to child and reducing the risk of transmission using antiretroviral drugs are critical in reducing mother-to-child transmission (PMTCT) of HIV. To assess MTCT knowledge, respondents were asked whether HIV can be transmitted from mother to child through breastfeeding and whether a mother with HIV can reduce the risk of transmission to her baby by taking certain drugs during pregnancy (EDHS report, 2016). The report also reveals that 74 percent of women and 73 percent of men know that HIV can be transmitted through breastfeeding; 51 percent of women and 61 percent of men know that the risk of mother-to-child transmission can be reduced if the mother takes special drugs during pregnancy. Overall, 48 percent of women and 53 percent of men know that HIV can be transmitted by breastfeeding and that the risk of mother to-child transmission can be reduced by taking special drugs. Knowledge regarding PMTCT is higher in urban than in rural areas, is lowest in Somali and highest in Addis Ababa, and increases with increasing education and wealth. Few previous summary reports and studies have identified determinants of comprehensive Knowledge about HIV prevention among young in different areas of Ethiopia, However, most of them were conducted in specific areas of the country using cross sectional survey. Hence, this study will be carried out at national level using recent Ethiopian Demographic and Health Survey (EDHS) 2016 data to assess and analyze determinants of comprehensive knowledge about HIV prevention among 15-24 years young in Ethiopia. Since EDHS 2016 data is the most recently released data and could show us up to date status of the problem, the study was conducted to identify the current gaps and supplement the past studies. Hence, it could be utilized as a reference for health care providers, health care educators, policy makers, and future researchers in this and/or related fields.

Consequently, the findings of this study could be valuable in addressing the major determinants of comprehensive knowledge about HIV prevention among 15-24 years young in Ethiopia, recommend the appropriate controlling model for policy makers and stake holders and the result of this study can also be used as a source of information for other researchers.

\section{Methods and Materials}

\subsection{Study Area}

The Federal Democratic republic of Ethiopia is located in the north-eastern part of Africa known as the Horn of Africa. The country has a total surface area of approximately 1.1 million square kilometers. Its topography ranges from peaks as high as $4550 \mathrm{~m}$ above sea level at Mt Ras Dashen in the north, to land $110 \mathrm{~m}$ below sea level in the 
Afar Depression. Ethiopia is a land-locked country, sharing a border with six countries: Eritrea and Sudan in the north, Djibouti and Somalia in the east, Kenya in the south and South Sudan in the west.

\subsection{Data Description}

The sampling frame used for the 2016 EDHS is the Ethiopia Population and Housing Census (PHC), which was conducted in 2007 by the Ethiopia Central Statistical Agency (CSA). The 2016 Ethiopia Demographic and Health Survey (EDHS) is the fourth Demographic and Health Survey conducted in Ethiopia. It was implemented by the CSA at the request of the Ministry of Health (MoH). Data collection took place from January 18, 2016, to June 27, 2016. Additionally, the 2016 EDHS included about comprehensive Knowledge about HIV prevention among 15-24 years Young in Ethiopia. Knowledge of HIV status helps HIV-negative individuals make specific decisions to reduce risk and increase safer sex practices so that they can remain disease free. Among those who are HIV infected, knowledge of their status allows them to take action to protect their sexual partners, to access treatment, and to plan for the future. Increasing general knowledge about prevention of HIV from mother to child and reducing the risk of transmission using antiretroviral drugs are critical in reducing mother-to-child transmission (MTCT) of HIV (EDHS report, 2016).

\subsection{Study Variables}

The dependent variable for this study is comprehensive Knowledge about HIV prevention among 15-24 years Young in Ethiopia; Knowledge of HIV prevention is defined as knowing that both condoms use and limiting sexual intercourse to one uninfected partner are HIV prevention methods, knowing that a healthy-looking person can have HIV. This was obtained by merging all the variables of comprehensive knowledge about HIV prevention. No (0) Yes (1) while the predictor variables included in the study were listed in Table 1 below.

\subsection{Method of Data Analysis}

In this study the binary logistic regression analysis was employed to identify determinant factors of knowledge about HIV prevention among 15-24 years young in Ethiopia.

\subsubsection{Logistic Regression Analysis}

Logistic regression model is a statistical technique for predicting the probability of an event, given a set of predictor variables. The binary logistic regression procedure empowers one to select the predictive model for dichotomous dependent variables. It describes the relationship between a dichotomous response variable and a set of explanatory variables. The explanatory variables may be continuous or discrete (McCullagh and Nelder, 1989). Logistic regression is useful for situations in which you want to be able to predict the presence or absence of a characteristic or outcome based on values of a set of predictor variables. It is similar to a linear regression model but is suited to models where the dependent variable is dichotomous. Logistic regression coefficients can be used to estimate odds ratios for each of the independent variables in the model. Binary response models are of major importance in the social sciences as well as in demography since many social phenomena are discrete or qualitative rather than continuous or quantitative in nature. In such studies, the logistic regression model has become the statistical model of choice (Agresti, 2007).

For this study, the binary logistic regression model was used to investigate effect of predictors on the probability of the response variables (comprehensive knowledge about HIV prevention among 15-24 years young) ( $Y_{i}$ ) in Ethiopia which is defined as follows. $Y_{i}$ takes a value 1 if the 15-24 years young had comprehensive Knowledge about HIV prevention and 0 other wise. Where: $-\mathrm{i}=1,2 \ldots \mathrm{n}$; where: $-\mathrm{n}$ is the number of sampled young 15-24 age years. The coefficient is interpreted as the change in the log-odds of young had Knowledge about HIV prevention per unit change of the corresponding continuous covariate. In case of categorical predictor variable, it is interpreted as the log-odds of young had knowledge about HIV prevention given a category compared to the reference category (Dayton, 1992).

If for a particular explanatory variable or group of explanatory variables, the Wald test is significant, then we would conclude that the parameters associated with these variables are significantly different from zero, so that the variables should be included in the model. 
Table 1. List of Independent Variables and Categories

\begin{tabular}{|c|c|}
\hline Variables & Categories \\
\hline \multirow{2}{*}{ Age } & Male \\
\hline & Female \\
\hline \multirow{2}{*}{ Place of residence } & Urban \\
\hline & Rural \\
\hline \multirow{4}{*}{ Education level } & No education \\
\hline & Primary \\
\hline & Secondary \\
\hline & Higher \\
\hline \multirow{9}{*}{ Respondent's occupation } & Not working \\
\hline & Professional/technical/managerial \\
\hline & Clerical \\
\hline & Sales \\
\hline & Agricultural - employee \\
\hline & Services \\
\hline & Skilled manual \\
\hline & Unskilled manual \\
\hline & Others \\
\hline \multirow{5}{*}{ Wealth index } & Poorest \\
\hline & Poorer \\
\hline & Middle \\
\hline & Richer \\
\hline & Richest \\
\hline \multirow{6}{*}{ Current marital status } & Never in union \\
\hline & Married \\
\hline & Living with partner \\
\hline & Widowed \\
\hline & Divorced \\
\hline & No longer living together/separated \\
\hline \multirow{2}{*}{ Sex } & Male \\
\hline & Female \\
\hline \multirow{6}{*}{ Religion } & Orthodox \\
\hline & Catholic \\
\hline & Protestant \\
\hline & Muslim \\
\hline & Traditional \\
\hline & Other \\
\hline \multirow{4}{*}{ Partner's Education Level } & No education \\
\hline & Primary \\
\hline & Secondary \\
\hline & Higher \\
\hline \multirow{11}{*}{ Region } & Tigray \\
\hline & Afar \\
\hline & Amhara \\
\hline & Oromia \\
\hline & Somali \\
\hline & Benishangul \\
\hline & SNNPR \\
\hline & Gambela \\
\hline & Harari \\
\hline & Addis Ababa \\
\hline & Dire dawa \\
\hline \multirow{2}{*}{ Media exposure } & No \\
\hline & Yes \\
\hline
\end{tabular}




\section{Results}

The major objective of this study is identify determinant factors of knowledge about HIV prevention among 15-24 years young. The data analysis was done using SPSS and STATA. The results of the analysis are divided into the Descriptive analysis and results of Binary logistic regression (Inferential Statistics). These results and their discussions are presented in the following sections.

\subsection{Results}

Table 2. Proportions of Knowledge about HIV Prevention by General Characteristics

\begin{tabular}{|c|c|c|c|}
\hline Variables & Categories & Frequency & Percentage \\
\hline \multirow{9}{*}{ Occupation } & Not working & 6171 & $58.7 \%$ \\
\hline & Professional/technical/managerial & 306 & $2.9 \%$ \\
\hline & Clerical & 137 & $1.3 \%$ \\
\hline & Sales & 1514 & $14.4 \%$ \\
\hline & Agricultural - employee & 1134 & $10.8 \%$ \\
\hline & Services & 476 & $4.5 \%$ \\
\hline & Skilled manual & 343 & $3.3 \%$ \\
\hline & Unskilled manual & 181 & $1.7 \%$ \\
\hline & Others & 258 & $2.5 \%$ \\
\hline \multirow{5}{*}{ Wealth index } & Poorest & 2557 & $24.3 \%$ \\
\hline & Poorer & 1119 & $10.6 \%$ \\
\hline & Middle & 4475 & $42.5 \%$ \\
\hline & Richer & 1204 & $11.4 \%$ \\
\hline & Richest & 1165 & $11.1 \%$ \\
\hline \multirow{6}{*}{ Current marital status } & Never in union & 6275 & $59.6 \%$ \\
\hline & Married & 3409 & $32.4 \%$ \\
\hline & Living with partner & 175 & $1.7 \%$ \\
\hline & Widowed & 26 & $0.2 \%$ \\
\hline & Divorced & 473 & $4.5 \%$ \\
\hline & No longer living together/separated & 162 & $1.5 \%$ \\
\hline \multirow{2}{*}{ Sex } & Male & 4408 & $41.9 \%$ \\
\hline & Female & 6112 & $58.1 \%$ \\
\hline \multirow{6}{*}{ Religion } & Orthodox & 4325 & $41.1 \%$ \\
\hline & Catholic & 55 & $0.5 \%$ \\
\hline & Protestant & 1785 & $17.0 \%$ \\
\hline & Muslim & 4286 & $40.7 \%$ \\
\hline & Traditional & 36 & $0.3 \%$ \\
\hline & Other & 33 & $0.3 \%$ \\
\hline \multirow{4}{*}{ Partner's Education level } & No education & 2094 & $20.0 \%$ \\
\hline & Primary & 5477 & $52.2 \%$ \\
\hline & Secondary & 2585 & $24.6 \%$ \\
\hline & Higher & 338 & $3.2 \%$ \\
\hline \multirow{2}{*}{ Media exposure } & No & 8447 & $80.6 \%$ \\
\hline & Yes & 2033 & $19.4 \%$ \\
\hline
\end{tabular}

Source: Computed from EDHS, 2016

The general objective of this study was to assess and pinpoint factors associated with knowledge about HIV prevention among 15-24 years young in Ethiopia. The data used for this analysis was 2016 EDHS.

\subsubsection{Descriptive Results}

The study was conducted on 10,520 young people age $15-24$ of which $41.9 \%$ were male and the rest $58.1 \%$ female. The Occupation of the 15-24 years young is regarded as an important factor to assess comprehensive knowledge about HIV prevention among 15-24 years young, the surveyed young were categorized in to different occupation categories. The result confirmed that $58.7 \%$ of the young 15-24 years in Ethiopia were working, and the rest about 
$41.3 \%$ were with occupation categories such as, Sales, professional, agriculture employee, services, skilled manual, unskilled manual and others. The analysis of the wealth category of those young among 15-24 years indicates that $34.9 \%, 42.5 \%$ and $22.5 \%$ were poor, middle class and rich, respectively. Most of the 15-24 years young were currently never in union $(59.6 \%$ ), while the remaining $39.4 \%$ were either married, divorced or no longer living together. Religion is another important characteristic of the population under study and the descriptive result depicts that about $58.6 \%$ of the $15-24$ years young were Christians, $40.7 \%$ were Muslim and the remaining $0.6 \%$ were accounted into other religion category. (Table2).

The education status was considered as an important factor for the investigation of comprehensive knowledge about HIV prevention among 15-24 years young in Ethiopia. Accordingly, the result shows that of the total surveyed young, $26.5 \%$ were without education, $40.4 \%$ had primary education while the remaining $33.1 \%$ had secondary and higher education. Accordingly, the result shows that of the total surveyed $15-24$ years young, $26.5 \%$ were without education, $40.4 \%$ had primary education while the remaining $33.1 \%$ had secondary and higher education. Most of the $15-24$ years young in Ethiopia were currently married $(94.6 \%)$, while the remaining $5.4 \%$ were either never married or formerly married. Media exposure and partner's education level were another important variables used to characterize the surveyed population of the study.

The proportion of young among 15-24 years in Ethiopia is different from urban to rural. The study explored percentages of $15-24$ years young and accordingly $22.5 \%$ of them live in urban area of the country while the remaining $77.5 \%$ life was based in rural area of the country. The result of the study further generalized that of the total surveyed young among $15-24$ years, $21.9 \%$ were without education, $46 \%$ had primary education while the remaining $22.1 \%$ had secondary and higher education (Table 2).

The status of knowledge about HIV prevention among 15-24 years young in Ethiopia is different from region to region in the country. The study explored percentages of knowledge about HIV prevention among 15-24 years young across regions of Ethiopia and accordingly those 15-24 years young from Addis ababa city takes the highest proportion, $46 \%$, whereas those from somali region shares smallest proportion, $9.7 \%$. The result of the study further generalized that the status on comprehensive knowledge about HIV prevention among 15-24 years young in Ethiopia is $30.72 \%$ prior to the survey year.

Table 3. Proportion of 15-24 Years Young by Place of Residence and Education Status in Ethiopia

\begin{tabular}{llcc}
\hline & Variables & Frequency & Percent \\
\hline \multirow{2}{*}{ Place of residence } & Urban & 2334 & $22.5 \%$ \\
& Rural & 8186 & $77.5 \%$ \\
\multirow{3}{*}{ Educational level } & No education & 2304 & $21.9 \%$ \\
& Primary & 4837 & $46.0 \%$ \\
& Secondary & 2351 & $22.3 \%$ \\
& Higher & 1028 & $9.8 \%$ \\
\hline
\end{tabular}

Source: Computed from EDHS, 2016

\subsubsection{Determinants of Knowledge about HIV Prevention among 15-24 Years Young in Ethiopia}

As per briefing in the methodology part, binary logistic model was employed to explore determinants of comprehensive knowledge about HIV prevention among 15-24 years young in Ethiopia. This model uses maximum likelihood technique which is an iterative procedure for estimation of parameters. The Wald $\gamma^{2}$ statistic as indicated was statistically significant $\mathrm{P}$ - value $(\mathrm{P}<0.000)$ and the model has strong explanatory power to predict the probability of comprehensive knowledge about HIV prevention among 15-24 years young in Ethiopia. The coefficients and odds ratio of the logistic model are given in Table 4 and possible discussion and interpretations of these variables are as follows.

Age of 15-24 years young negatively and significantly affected knowledge about HIV prevention among 15-24 years young in Ethiopia. Similarly, Place of residence positively and significantly affected comprehensive knowledge about HIV prevention among 15-24 years young in the country. Accordingly, 15-24 years young who live in rural 
area were 0.77 times less likely to acquire comprehensive knowledge about HIV prevention in Ethiopia than young who live in urban area of Ethiopia.

Table 4. The Estimates of Coefficients and Odds Ratio of Binary Logistic Regression

\begin{tabular}{|c|c|c|c|c|c|c|}
\hline Variables & $\mathrm{B}$ & S.E. & Wald & Df & Sig. & Odds ratio \\
\hline Age & 0.162 & 0.010 & 256.964 & 1 & 0.000 & 1.176 \\
\hline Place residence (1) & -0.259 & 0.091 & 8.036 & 1 & 0.005 & 0.772 \\
\hline Education level (no education) & & & 21.229 & 3 & 0.000 & \\
\hline Primary & -0.398 & 0.109 & 13.197 & 1 & 0.000 & 0.672 \\
\hline Secondary & -0.184 & 0.094 & 3.787 & 1 & 0.052 & 0.832 \\
\hline Higher & -0.036 & 0.093 & 0.153 & 1 & 0.696 & 0.964 \\
\hline Occupation & & & 17.661 & 8 & 0.024 & \\
\hline Professional/technical/managerial & -0.114 & 0.145 & 0.620 & 1 & 0.431 & 0.892 \\
\hline Clerical & 0.375 & 0.196 & 3.653 & 1 & 0.056 & 1.455 \\
\hline Sales & -0.059 & 0.153 & 0.149 & 1 & 0.700 & 0.943 \\
\hline Agricultural - employee & -0.086 & 0.159 & 0.295 & 1 & 0.587 & 0.917 \\
\hline Services & -0.040 & 0.175 & 0.052 & 1 & 0.820 & 0.961 \\
\hline Skilled manual & -0.271 & 0.188 & 2.094 & 1 & 0.148 & 0.762 \\
\hline Unskilled manual & 0.157 & 0.218 & 0.520 & 1 & 0.471 & 1.170 \\
\hline Windex & & & 20.787 & 4 & .000 & \\
\hline Poorer & -0.476 & 0.107 & 19.896 & 1 & 0.000 & 0.622 \\
\hline Middle & -0.337 & 0.110 & 9.439 & 1 & 0.002 & 0.714 \\
\hline Richer & -0.356 & 0.108 & 10.932 & 1 & 0.001 & 0.700 \\
\hline Richest & -0.354 & 0.105 & 11.442 & 1 & 0.001 & 0.702 \\
\hline Marital status & & & 17.211 & 5 & 0.004 & \\
\hline Married & 0.191 & 0.187 & 1.040 & 1 & 0.308 & 1.211 \\
\hline Living with partner & 0.249 & 0.189 & 1.732 & 1 & 0.188 & 1.282 \\
\hline Widowed & 0.167 & 0.248 & 0.456 & 1 & 0.499 & 1.182 \\
\hline Divorced & 1.122 & 0.461 & 5.913 & 1 & 0.015 & 3.071 \\
\hline No longer living together/separated & 0.558 & 0.209 & 7.165 & 1 & 0.007 & 1.748 \\
\hline $\operatorname{Sex}(1)$ & 0.709 & 0.049 & 212.969 & 1 & 0.000 & 2.031 \\
\hline Religion & & & 5.241 & 5 & 0.387 & \\
\hline Catholic & 0.362 & 0.441 & 0.672 & 1 & 0.412 & 1.436 \\
\hline Protestant & 0.022 & 0.552 & 0.002 & 1 & 0.969 & 1.022 \\
\hline Muslim & 0.372 & 0.441 & 0.712 & 1 & 0.399 & 1.451 \\
\hline Traditional & 0.311 & 0.442 & 0.498 & 1 & 0.481 & 1.365 \\
\hline Others & -0.537 & 0.667 & 0.647 & 1 & 0.421 & 0.585 \\
\hline Peduclevel & & & 2.507 & 3 & 0.474 & \\
\hline Primary & 0.048 & 0.134 & 0.129 & 1 & 0.719 & 1.049 \\
\hline Secondary & -0.042 & 0.128 & 0.109 & 1 & 0.741 & 0.959 \\
\hline Higher & 0.002 & 0.132 & 0.000 & 1 & 0.990 & 1.002 \\
\hline Region & & & 114.618 & 10 & 0.000 & \\
\hline Afar & 0.680 & 0.119 & 32.607 & 1 & 0.000 & 1.973 \\
\hline Amhara & 0.495 & 0.124 & 15.989 & 1 & 0.000 & 1.641 \\
\hline Oromia & 0.276 & 0.125 & 4.857 & 1 & 0.028 & 1.318 \\
\hline Somali & 0.445 & 0.115 & 14.988 & 1 & 0.000 & 1.561 \\
\hline Benishangul gumuz & -0.243 & 0.127 & 3.656 & 1 & 0.056 & 0.784 \\
\hline SNNPR & -0.103 & 0.133 & 0.601 & 1 & 0.438 & 0.902 \\
\hline Gambela & 0.275 & 0.127 & 4.684 & 1 & 0.030 & 1.317 \\
\hline Harari & 0.042 & 0.135 & 0.098 & 1 & 0.754 & 1.043 \\
\hline Addis Adaba & 0.011 & 0.126 & 0.008 & 1 & 0.930 & 1.011 \\
\hline Dire Dawa & 0.278 & 0.106 & 6.874 & 1 & 0.009 & 1.321 \\
\hline Med exposure(1) & 0.206 & 0.055 & 13.895 & 1 & 0.000 & 0.814 \\
\hline Constant & -4.330 & 0.580 & 55.726 & 1 & 0.000 & 0.013 \\
\hline
\end{tabular}

Source: Computed from EDHS, 2016. Significance levels: 1\%, 5\% and 10\%, N = 5063 $\quad \mathrm{P}>0.000 \quad$ Wald Statistic $=1038.02$ 
Education status is another significant determinant of comprehensive knowledge about HIV prevention among 15-24 years young in Ethiopia. 15-24 years Young with primary education were 0.67 times less likely to have comprehensive knowledge about HIV prevention compared to those without formal education. 15-24 years young with secondary education were 0.83 times less likely to have knowledge about HIV prevention compared to those without formal education. 15-24 years young with higher education were 0.964 times less likely to have knowledge about HIV prevention compared to those without formal education. Occupation is also among the important variables significantly influenced knowledge about HIV prevention among 15-24 years young and accordingly 15-24 years young in the country were 0.9 times less likely to have comprehensive knowledge about HIV prevention than not working young, whereas 15-24 years young were 1.45 more likely have knowledge about HIV than not working young.

Wealth index is also among the important variables significantly influenced comprehensive knowledge about HIV prevention among 15-24 years young and accordingly poorer young were 0.66 times less likely to have comprehensive knowledge about HIV prevention than poorest 15-24 years young, whereas 15-24 years young of poor wealth were 0.71 times less likely to have knowledge about HIV prevention among 15-24 years than poorer young while 15-24 years young of middle wealth, rich and richer were $0.71,0.70$ and 0.70 times less likely to have comprehensive knowledge about HIV prevention than poorest young respectively. Marital status of the 15-24 has also significant effect on comprehensive knowledge about HIV prevention. Accordingly Married, living with partner, widowed, divorced and separated 15-24 years Young were 1.21, 1.28, 1.18, 3.07 and1.75 more to have comprehensive knowledge about HIV prevention respectively compared to those single in Ethiopia. Similarly, 15-24 years young female were 2.03 times more likely to have Knowledge about HIV prevention than male young in Ethiopia. Region is one of the significant variables influenced comprehensive knowledge about HIV prevention among 15-24 years young in Ethiopia. The result of odd ratio confirmed that the 15-24 years Young living in Afar region are 1.97 times more likely to have comprehensive knowledge about HIV prevention among 15-24 years young compared to the young living in Tigray region whereas the 15-24 years Young living in Amhara region were 1.64 times more likely to comprehensive knowledge about HIV prevention compared to the children living in Tigray region. In addition to this the 15-24 years young living in Oromia region were 1.32 times more likely to comprehensive knowledge about HIV prevention compared to the children living in Tigray region whereas the 15-24 years young living in somali region were 1.56 times more likely to have comprehensive knowledge about HIV prevention among 15-24 years young compared to the children living in Tigray region. The study result further depicted that the 15-24 years young living in Gambella region were 1.32 times more likely to have knowledge about HIV prevention than the children living in Tigray region and the 15-24 years young living in Dire Dawa region were 1.32 times more likely to have comprehensive knowledge about HIV prevention than the children living in Tigray region.

Similarly, the model result highly confirmed that 15-24 years young who have all day's media exposure were 0.81 times less likely to have comprehensive knowledge about HIV prevention than those who have not all day's media exposure.

\section{Discussion}

The study result showed that region was significantly associated with comprehensive knowledge about HIV prevention among 15-24 years young in Ethiopia which is in line with study findings by (CSA, 2005 and EDHS, 2011).

Our results show that variables such as education level and sex were significantly associated with comprehensive knowledge about HIV prevention among 15-24 years young in Ethiopia. The 15- 24 years young who have at least secondary level of education were more likely to have Knowledge about HIV prevention than young with no formal education which is consistent with study result obtained by(HAAPCO, 2008).

Another finding of this study also indicated that occupation and place of wealth index significantly associated with comprehensive knowledge about HIV prevention among 15-24 years young in Ethiopia which is in line with study findings by (Oljira, L., 2013). This study also revealed that the marital status is significantly associated with comprehensive knowledge about HIV prevention among 15-24 years young in Ethiopia at 5\% level of significance from which we conclude marital status determines the comprehensive knowledge about HIV prevention in Ethiopia.

This study also showed that the education level is significantly associated with comprehensive knowledge about HIV prevention among 15-24 years young were more likely to have knowledge about HIV prevention if they are rich 
compared with those who are poor which is consistent with the study result obtained by (Oljira, L., 2013). Religion and parents' education level were not associated with comprehensive knowledge about HIV prevention among 15-24 years young in Ethiopia. This means these two variables didn't have any influence on comprehensive knowledge about HIV prevention in the study area.

\section{Conclusion and Recommendations}

The result of this study has clearly indicated that $30.7 \%$ of comprehensive knowledge about HIV prevention among 15-24 years young in Ethiopia. The challenges however are that most orthodox religion follower women, women without education, women with poor wealth category still seem not have comprehensive knowledge about HIV prevention among 15-24 years young in Ethiopia and this affects the percentage of comprehensive knowledge about HIV prevention among 15-24 years young in Ethiopia. Our study adds to the existing body of literature regarding the factors that influence comprehensive knowledge about HIV prevention among 15-24 years young in Ethiopia in low and middle income countries. Study findings highlight several potential avenues to improve comprehensive knowledge about HIV prevention among 15-24 years young in Ethiopia rates. In addition, providing information and education about the benefits of comprehensive knowledge about HIV prevention among 15-24 years young are important. age, place of residence, education level, occupation, wealth index, marital status sex, region and media exposure provide a good opportunity to enhance the awareness about comprehensive knowledge about HIV prevention among 15-24 years young in Ethiopia and other HIV related health services. Based on the result of the study, the following recommendations are forwarded. Firstly, government, health bureau, Health workers and others should increase the awareness of 15-24 years young in the country with no education and poor wealth category about comprehensive knowledge about HIV prevention among 15-24 years young in Ethiopia by providing equal accessibility of health facilities. Secondly, Special attention should be given by the Health workers and government for the 15-24 years young in the country to decrease mortality rate related to HIV.

\section{Acknowledgement}

I am grateful for CSA since the data used for this study was obtained from CSA (Ethiopia).

\section{References}

Bradley, S. E. K., Croft, T. N., Fishel, J. D., \& West off, C. F. (2012). Revising Unmet Need for Family Planning. DHS Analytical Studies No. 25. Calverton, Maryland, USA: ICF International.

UNAIDS. (2008). Report on the Global AIDS Epidemic. Geneva.

UNAIDS \& WHO. (2009). AIDS Epidemic Update.

Federal Democratic Republic of Ethiopia Ministry of Health Health Sector Development Program IV: 2010/11 2014/15: October 2010.

CDC Ethiopia. (2013). Top 10 Causes of Death in Ethiopia fact sheet: CDC-Ethiopia U.S. Embassy.

Central Statistical Agency, Ethiopia Demographic and Health Survey. (2016). Central Statistical Agency, Addis Ababa, Ethiopia, 2016.

McCullagh, P., \& Nelder. (1980). Regression Models for Ordinal Data (with discussion). Journal of the Royal Statistical Society Series B, 42, 109-142.

Agresti, A. (2007). An Introduction to categorical data analysis (2nd Ed.). New York: John Wiley \& Sons.

Dayton, C. M. (1992). Logistic Regression Analysis. Department of Measurement, Statistics and Evaluation, University of Maryland.

Central Statistical Agency (CSA) [Ethiopia] and ORC Macro. (2006). Ethiopia Demographic and Health Survey 2005. Addis Ababa, Ethiopia, and Calverton, Maryland, USA: Central Statistical Agency and ORC Macro.

Central Statistical Agency (CSA) [Ethiopia] and ICF Macro. (2012). Ethiopia Demographic and Health Survey 2011. Addis Ababa, Ethiopia, and Calverton, Maryland, USA: Central Statistical Agency and ICF Macro.

HAPCO and World Bank, HIV/AIDS in Ethiopia: An Epidemiological Synthesis, HAPCO and World Bank, 2008.

Oljira, L., Berhane, Y., \& Worku, A. (2013). Assessment of comprehensive HIV/AIDS knowledge level among 
in-school adolescents in eastern Ethiopia. Journal of the International AIDS Society, 16(1). https://doi.org/10.7448/IAS.16.1.17349 